\title{
Trabalho e desenvolvimento: a realidade rural e a questão social
}

\section{Work and developmental: the rural reality and the social issue}

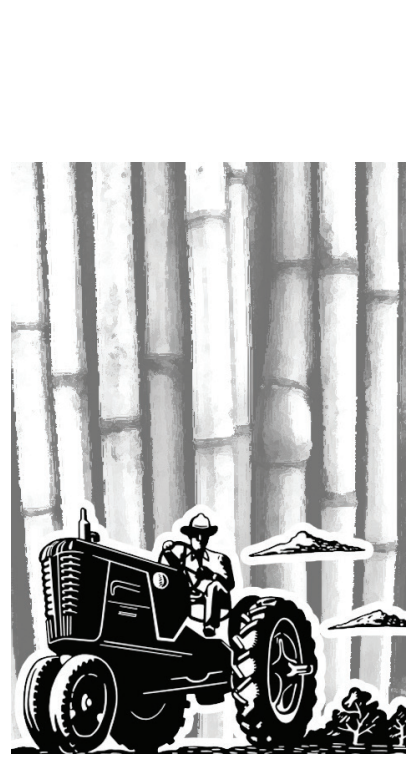

\begin{abstract}
Resumo: O reconhecimento da centralidade do trabalho no cotidiano profissional do Serviço Social nem sempre permite uma análise crítica da política pública social. Este artigo procura evidenciar a materialização do trabalho como eixo fundante das relações estabelecidas na atual sociabilidade e faz isso por meio da interlocução entre mundo do trabalho e política de assistência social em municípios de pequeno porte cuja principal atividade econômica é a canavicultura. O objetivo é fornecer subsídios para a apreensão da relação entre trabalho, questão social e a particularidade do rural no cotidiano do profissional de Serviço Social.
\end{abstract}

Palavras-chave: Trabalho. Serviço Social. Questão agrária. Política de assistência social.

\begin{abstract}
The recognition of the centrality of work in the professional Social Work daily life does not always allow a critical analysis of the social public policy. This article seeks to highlight the materialization of work as the founding axis of the relations established in the current sociability, and it does so by making the Social Work world of labor and policies interlocutors in towns whose main economic activity is the farming of sugar cane. The aim is to provide subsidies to understand the relation among work, social issue and the particularity of the rural in the professional Social Work daily life.
\end{abstract}

Keywords: Work. Social Work. Agrarian issue. Social assistance policy.

* Professora doutora e livre-docente do Departamento de Serviço Social da Faculdade de Ciências Humanas e Sociais de Franca/SP, câmpus da Unesp, São Paulo; Brasil, membro do grupo de estudos e pesquisa Teoria social de Marx e Serviço Social.E-mail: raquelssfranca@yahoo.com.br. 


\section{Introdução}

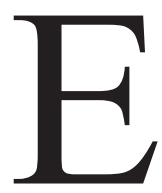

ste artigo discute a relação entre trabalho e política pública social, com foco na assistência social em municípios de pequeno porte. O objetivo deste texto é demonstrar a relação direta entre as demandas dessa política e as condições de trabalho resultantes do desenvolvimento agrário em curso, tendo como referência pequenos municípios do interior paulista onde a canavicultura é a principal atividade econômica.

Nos diferentes espaços profissionais, o assistente social precisa apreender as mediações entre as demandas postas em seu cotidiano e as configurações do mundo do trabalho. Quando se trata de municípios de pequeno porte, cuja economia gira em torno das atividades monocultoras da agricultura capitalista, o debate sobre a desertificação do campo e as condições precárias do assalariados rurais têm que compor a análise dos profissionais porque essa será a base sobre a qual emergem as demandas de seu cotidiano, em diversos espaços sócio-ocupacionais.

O Serviço Social não tem um grande acúmulo no debate sobre temática agrária para subsidiar a análise das mediações existentes entre modelo agrícola e refrações da questão social em municípios cuja economia é voltada para as atividades do agronegócio. Ainda que o debate sobre o fundamento da questão social como decorrente dos conflitos entre capital e trabalho e sua centralidade nas condições de produção e reprodução desse modelo de sociabilidade seja a base fundamental, é preciso apreender as mediações que perfazem e evidenciam as singularidades das demandas trazidas pelo trabalho rural. Em municípios pequenos, os espaços sócio-ocupacionais são, em grande medida, permeados pelas demandas trazidas pelas precárias relações de trabalho ou pelo desemprego permanente dos trabalhadores rurais.

Apreender essa realidade poderá contribuir com a desmistificação da modernidade reclamada pelo agronegócio e, também, para uma atuação do assistente social mais qualificada para o atendimento desse público que, de forma cada vez mais frequente, tem se tornado usuário da política de assistência social.

O debate sobre o tema terá como referência os dados do projeto Trabalho e Política Pública: A Participação do Trabalhador Rural na Política de Seguridade Social ${ }^{1}$ efetivado no período de 2010 a 2013. A pesquisadora responsável pertence

1. Esse projeto foi financiado pelo CNPq por meio do edital MCT/CNPq/MEC/Capes n. 02/2010 Ciências Humanas, Sociais e Sociais Aplicadas, e contou em sua execução com uma equipe de pesquisa que incluiu profissionais e estudantes de Serviço Social e área afins. 
ao grupo Teoria Social de Marx e Serviço Social na linha de pesquisa Questão Agrária e Serviço Social da Unesp de Franca.

\section{A centralidade do trabalho e projetos de desenvolvimento}

O trabalho é crucial no desenvolvimento do ser social. Essa centralidade do trabalho, que permanece até os dias atuais, possui as configurações específicas desse momento histórico, conforme será aqui abordado. Isso, no entanto, não significa que essa categoria, mesmo sendo fundante do ser social, possa sozinha explicar o conjunto das relações sociais. A realidade é composta por diversos complexos sociais em interação. Como afirma Marx (1982, p. 14) a realidade é "uma rica totalidade de determinações e relações diversas".

Somente uma perspectiva de totalidade pode se aproximar deste movimento da realidade concreta. A centralidade do trabalho, expressa, portanto, a sua prioridade ontológica como elemento constitutivo do ser social. No entanto, atribuir prioridade ontológica a uma categoria não significa isolá-la ou mesmo hierarquizá-la do ponto de vista do valor.

Lukács explica o significado da prioridade ontológica relacionando o ser a consciência, produção e reprodução:

Do ponto de vista ontológico, isso significa simplesmente que pode existir o ser sem a consciência, enquanto toda consciência deve ter como pressuposto, como fundamento, algo que é. Mas disso não deriva nenhuma hierarquia de valor entre ser e consciência [...] O mesmo vale, no plano ontológico, para a prioridade da produção e da reprodução do ser humano em relação a outras funções. $(1979$, p. 19)

O desenvolvimento da capacidade teleológica do ser humano foi resultante de constantes processos de aprimoramento da relação do homem com a natureza e com outros seres humanos, de maneira a fazer recuar as barreiras naturais e potencializar as suas ações sobre o mundo.

Foi a partir do trabalho que o homem construiu um mundo especificamente humano e, com a satisfação de suas necessidades mais elementares, desenvolveu outras mais complexas e diversificadas. Como afirma Lukács (2004, p. 62): “A través del trabajo se convierte por un lado, en modelo de toda práxis social em la 
medida en que esta - aun cuando a través de mediaciones muy diversificadas - se realizam siempre posiciones teleológicas, en ultima instancia, de ordem material".

Historicamente, os homens foram desenvolvendo diferentes formas de produzir e se relacionar. O capitalismo é mais uma dessas formas e que tem como base a apropriação privada dos frutos do trabalho por parte do capital, o que faz com que este expanda cada vez mais. Em contrapartida, expressa uma contradição fundamental: a crescente pauperização (relativa ou absoluta) daquele que produziu os produtos em forma de trabalho assalariado.

Marx, em seus estudos sobre a sociabilidade capitalista, mostra como o embate de classes entre os trabalhadores e o capital decorre de algo estrutural: o fato de a produção realizar-se socialmente, porém a apropriação dos frutos do trabalho ser privada. A exploração nas relações de trabalho na sociedade capitalista é, portanto, ineliminável.

As contradições que engendram o modo de produção capitalista são sustentadas por mecanismos ideológicos poderosos que fazem com que, no nível da aparência, a realidade social se apresente como realidade natural. O homem como sujeito construtor e transformador da realidade do mundo humano passa a não se identificar como tal.

A transformação da realidade social em fatos naturais decorre fundamentalmente pelo enigma representado pela mercadoria, que faz com que as relações entre os homens assumam o caráter de intercâmbio entre coisas.

O misterioso da forma mercadoria consiste, portanto, simplesmente no fato de que ela reflete aos homens as características sociais do seu próprio trabalho, como características objetivas dos próprios produtos de trabalho, como propriedades naturais sociais dessas coisas e, por isso, também reflete a relação social dos produtores com o trabalho total como uma relação social existente fora deles, entre objetos. [...] Não é mais nada que determinada relação social entre os próprios homens que para eles assume a forma fantasmagórica de uma relação entre coisas. (Marx, 1983, p. 71)

A naturalização das relações sociais é decorrente do modo de produção capitalista e de sua necessidade de ocultar os mecanismos de exploração advindos das relações de trabalho. A fragmentação do trabalho é condição fundamental para o processo de reificação, pois o trabalhador perde a condição de identificar-se como sujeito produtor da realidade social. Ainda em sua reflexões iniciais, Marx (2004) 
faz uma colocação essencial a respeito do processo de estranhamento provocado pelo trabalho sob o modo de produção capitalista, a qual dialoga diretamente com as características do trabalho que serão tratadas neste estudo.

A efetivação do trabalho tanto aparece com desefetivação que o trabalhador é desefetivado até morrer de fome. A objetivação tanto aparece como perda do objeto que o trabalhador é despojado dos objetos mais necessários não somente à vida, mas também dos objetos do trabalho [...]. Quanto mais o trabalhador se desgasta trabalhando (ausarbeitet), tanto mais poderoso se torna o mundo objetivo, alheio (fremd) que ele cria diante de si, tanto mais pobre se torna ele mesmo, seu mundo interior, [e] tanto menos [o trabalhador] pertence a si próprio. (Marx, 2004, p. 80-81)

O antagonismo de classe é, portanto, decorrente das relações de produção em que os interesses do trabalho e do capital se opõem de maneira explícita ou são mediados por mecanismos ideológicos necessários à reprodução dessa sociabilidade.

$\mathrm{Na}$ atual fase de capitalismo monopolista, o Estado é direcionado para a manutenção dos superlucros capitalistas e para a reprodução de seus ideários, "e para tanto como poder político e econômico, o Estado desempenha uma multiplicidade de funções" (Netto, 1996, p. 21). Este passa a atuar de forma direta e indireta, de maneira a reproduzir os interesses do monopólio. Na concepção desse autor, o Estado atual é capturado pela lógica do capitalismo monopolista:

Tendencialmente o que esse verifica é a integração orgânica entre os aparatos privados dos monopólios e as instituições estatais. Donde uma explicável alteração não apenas na modalidade de intervenção do Estado (agora contínua, em comparação com o estágio concorrencial), mas nas estruturas que viabilizam a intervenção mesma: no sistema de poder político, os centros de decisão ganham crescente autonomia em relação às instâncias representativas formalmente legitimadas. (Netto, 1996, p. 22)

Segundo Netto, nesse Estado a preservação e o controle da força de trabalho é parte de suas funções primordiais e, mais que isso, ele é responsável por "regular a sua pertinência a níveis determinados de consumo e sua disponibilidade para a ocupação sazonal, bem como a instrumentalizar mecanismos gerais que garantam a sua mobilização e alocação em função das necessidades e projetos dos monopólio" (Idem, p. 23). 
No atual contexto, as transformações do mundo do trabalho ocorridas a partir da chamada terceira revolução tecnológica, resultante do avanço da robótica e da informática associado às novas formas de gestão do trabalho, tem trazido imensos desafios para a classe trabalhadora. Essas transformações têm provocado, de forma direta um processo de intensificação e precarização do trabalho de tamanha intensidade que, associado aos mecanismos ideológicos retomados pelas ideias neoliberais, tem trazido dificuldades de organização e luta dos diferentes segmentos da classe trabalhadora em termos planetários. Ainda que algumas manifestações de organização ou embates estejam retornando ao cenário político, prevalece no atual contexto uma hegemonia mundial do capital monopolista.

No Brasil, no final da década de 1980, uma série de mobilizações da classe trabalhadora foi fundamental para a incorporação na Constituição de 1988 de vários direitos sociais. Castelo (2012) discute que esse fato, associado à crise da dívida externa e a consequente estagflação decorrida nesta década, vai fazer com que as classes dominantes rearticulem suas alianças e promovam um amplo processo de reestruturação produtiva do parque industrial de maneira a incorporar a revolução tecnológica da microeletrônica e do toyotismo (Castelo, 2012b, p. 49).

A rearticulação da classe dominante desencadeou uma ofensiva ideológica neoconservadora, materializada no governo de Collor e, principalmente, no governo de Fernando Henrique Cardoso, por meio das políticas denominadas de social-liberais por Castelo (2012).

As ideias do chamado social-liberalismo são as respostas conservadoras para as crises geradas pela hegemonia neoliberal, materializadas no Consenso de Washington. Na realidade, tentava-se acrescentar uma agenda social à proposta neoliberal de maneira a diminuir as expressões mais graves da "questão social" sem mexer "nos fundamentos da vida mercantil generalizada no capitalismo" (Castelo, 2012b, 47).

No Brasil, o social-liberalismo tem sua implantação efetiva com o governo FHC (1995-2002), e pouca diferença teve das proposições das agências multilaterais de desenvolvimento claramente neoliberais.

Para o enfrentamento do quadro de desigualdade é feita uma proposta de construção de pactos sociais entre as classes sociais de maneira a todos se empenharem no sentido de reduzir a pobreza e a indigência no país. Ao discutir as causas da desigualdade no Brasil, Francisco Ferreira, um dos intelectuais defensores do social-liberalismo, afirma que: "Seria o nível formal de educação de cada indivíduo, na sua capacidade de competição no mercado de trabalho, que esse deveria buscar 
as causas primárias e fundamentais do pauperismo, e não nas relações estabelecidas entre as classes sociais" (2000, p. 144, apud Castelo, 2012, p. 57).

Nessa perspectiva, as estratégias de combate à pobreza deveriam investir não no aumento real do salário mínimo e dos benefícios previdenciários, mas sim "nas políticas sociais compensatórias (transferência direta de renda aos mais necessitados) e estruturais (democratização dos ativos de educação, terra e crédito)" (Castelo, 2012, p. 58).

O governo Lula (2003-2010) vai realizar uma política de combate a pobreza com o discurso de promover desenvolvimento pela via do crescimento econômico e da preocupação com o social. Na realidade, combinando uma política de desenvolvimento que aumenta o salário mínimo, indexa os benefícios sociais ao valor do salário e amplia os programas de transferência de renda, o governo diminui a desigualdade social sem, no entanto, alterar os problemas estruturais que promovem a concentração de riqueza e, com isso, realiza apenas uma leve desconcentração da renda que vem do trabalho.

A partir de 2003, o país apresentou clara tendência de queda nos indicadores de incidência de pobreza, extrema pobreza (indigência) e desigualdade de renda. Pelos dados da PNAD e estimativas realizadas pelo Ipea, em 2003, eram 61,4 milhões de pobres (36\%) e 21,6 milhões de indigentes (26\%). Em 2008, esses totais caem para 41,5 milhões $(23 \%)$ e $13,9 \%$ milhões (14\%), respectivamente. Isto corresponde a uma redução de mais de $30 \%$ na incidência da pobreza e de mais de $46 \%$ na incidência da extrema pobreza. Já a desigualdade de renda medida pelo Coeficiente de Gini que permaneceu no patamar de 0,60 por 20 anos, atinge seu menor valor em $2008(0,548)$. (Cobo, 2012, p. 178)

Cobo (2012) apresenta três elementos fundamentais que concorreram para a melhoria destes indicadores: o primeiro é uma conjuntura internacional favorável ao crescimento econômico, o que potencializou a geração de emprego e, consequentemente, a renda do trabalho afetou a renda familiar; o segundo foi a elevação do salário mínimo acima dos índices da inflação e a indexação dos benefícios previdenciários ao salário e, em terceiro lugar o aumento dos beneficiários dos programas de transferências de renda (Cobo, 2012, p. 178-181). A autora identifica que esse é o início de um longo caminho a ser percorrido rumo à diminuição da desigualdade, o que de fato não é a leitura deste trabalho.

Conforme salienta Gonçalves (2012b), a redução generalizada da desigualdade da renda no Brasil e na América Latina no início deste século deve-se a três 
fatores: o imperativo da governabilidade, o objetivo de perpetuação do poder dos grupos dirigentes e a evolução favorável da economia mundial.

A isso deve se acrescentar os elementos estruturais decorrentes da própria anarquia produtiva em tempos de monopólios globais, e temos aí a eminência dos Estados em recorrer a medidas paliativas no sentido de manter a atual ordem sociometabólica do capital.

Ainda que reconheçamos a necessidade de ações imediatas no sentido de corrigir os níveis extremos de desigualdade vivenciados no país, a transformação desse quadro é uma tarefa que envolve a própria reversão dessa sociabilidade que está assentada na propriedade privada e na exploração do trabalho. Em tempos de capital monopolista, as alianças dos setores dominantes e do Estado dificultam qualquer iniciativa de enfrentamento da questão social pela via estrutural. As alternativas buscadas fundamentalmente no âmbito das políticas públicas sociais, em especial as políticas de transferência de renda, constituem hoje as principais ações de vários governos em toda a América Latina, e não só no Brasil.

Diante do desemprego estrutural e da redução das proteções sociais decorrentes do trabalho, a tendência é a ampliação dos que demandam o acesso a serviço e benefícios de assistência social. São trabalhadores e suas famílias que, mesmo exercendo atividades laborativas, tem suas relações de trabalho marcadas pela informalidade e pela baixa renda. Em uma conjuntura social adversa, é relevante analisar o significado que os serviços e benefícios sociais como o Bolsa Família ou aposentadoria rural nas economias locais, especialmente nos pequenos municípios dependentes da agricultura, que em muitos casos constituem as mais significativas fontes de renda a movimentar o mercado interno de bens e serviços essenciais. (Couto, Yazbek e Raichelis, 2010, p. 46)

Mesmo com o aumento dos níveis de formalização do trabalho e redução do desemprego em algumas áreas, a atual configuração do mundo do trabalho é marcada por altos níveis de informalidade e precariedade. ${ }^{2}$

Os trabalhadores que estão em empregos formais são pressionados pela intensificação do trabalho e pela eminência do desemprego; aqueles que não conseguem trabalhos permanentes são impulsionados para o trabalho informal e temporário, sem acesso aos direitos conquistados historicamente pela classe trabalhadora.

2. Segundo a pesquisa do Centro de Estudos Sindicais e de Economia do Trabalho (Cesit), da Unicamp, “[...] em seis regiões metropolitanas [...] apontam que os trabalhadores têm menor estabilidade no emprego, trabalham mais do que a jornada legal e ganham menos" (Couto, Yazbek e Raichelis, 2010, p. 46-47). 
A ampliação do exército industrial de reserva vai ganhando novos contornos: são os descartados, os não empregáveis, aqueles a que o capital não precisa mais recorrer, nem mesmo temporariamente. Ocorre que são milhões em todo o mundo e também no Brasil, e para que haja a domesticação desse contingente potencialmente tensionador da ordem social pela sua própria condição de miséria, há de se criar alternativas no âmbito político e social. Daí a funcionalidade especialmente dos programas de transferência de renda, principal alternativa para a redução da pobreza extrema em toda a América Latina.

Assim o fato alertado por Mota (2006), a política de assistência social, ganha tamanha centralidade no cenário atual que se torna um fetiche.

As políticas de Seguridade Social passam a ser um elo entre a produção e a reprodução, principalmente quando consideradas instrumento de cobertura de riscos e vulnerabilidades do trabalho. Mas é pela via da cidadania que elas ganham destaque, adquirindo no plano jurídico-político a aparência de uma esfera autônoma em relação à produção. Por isso mesmo se constituem num mecanismo ideológico por excelência. (Mota, 2006, p. 10)

Como já destacado por Netto (1996), na atual fase do capital monopólico a anarquia produtiva desencadeia novas funções para o Estado, que deve não só preservar a ordem controlando as tensões e as lutas dos trabalhadores, mas também intervir no sentido de garantir sua reprodução social. Os resultados desse processo no âmbito do trabalho são catastróficos, e a maior evidência disso é que passam a depender dos programas assistenciais não somente o trabalhador sem acesso ao trabalho, mas também um amplo contingente da classe trabalhadora que, devido aos níveis de exploração e descarte a que está submetido, não consegue pela via do trabalho a sua própria reprodução e a de sua família.

Os contornos atuais do mundo do trabalho estão diretamente relacionados a forma como vem se estruturando as políticas de seguridade social. Como afirma Sitcovsky (2012, p. 227):

As formas de organização social do trabalho, historicamente, determinaram a arquitetura das políticas sociais. Isso significa dizer que o desenvolvimento histórico do trabalho exerce influência direta na definição do tipo, conteúdo, dos objetivos e do alcance das políticas sociais. 
A relação entre trabalho e política pública será evidenciada no universo específico dessa pesquisa que trata do acesso do trabalhador rural às políticas de seguridade social. No entanto, para fazer o debate dessa realidade, há de apresentar, mesmo que pontualmente, alguns elementos do atual modelo de desenvolvimento agrário e a configuração assumida pela política de seguridade, especialmente a assistência social.

\section{Breves considerações sobre a realidade rural e a política de seguridade social}

O último censo agropecuário de 2006 aponta a permanência de uma estrutura agrária extremamente concentrada. É o que evidencia abaixo a Tabela 1. As propriedades de até dez hectares somam 1.744 .540 imóveis e representam 33\% dos imóveis, mas ocupam 8.215.337 hectares, ou seja, 1,4\% da área. Em contrapartida, os imóveis com mais de dois mil hectares são menos de $1 \%$ dos imóveis $(0,8 \%)$ e ocupam 571.740.919 hectares, o que corresponde a 42,5\% do território. Se somarmos as propriedades de 10 a 100 hectares, temos 4.453 .698 imóveis (86\%), que ocupam uma área de 98.220 .873 hectares, o que significa 17,1 \% do território. As propriedades de 100 e 500 hectares somam 563.346 imóveis e ocupam 116.156 .530 hectares $(20,3 \%)$. Por outro lado, os imóveis com mais de 500 hectares somam 164.601 estabelecimentos e ocupam um território de 357.363 .517 hectares, o que equivale a $62,3 \%$ do território.

Tabela 1

\begin{tabular}{|l|c|c|c|c|c|}
\hline \multirow{2}{*}{$\begin{array}{c}\text { Estratos de área } \\
\text { total (ha) }\end{array}$} & \multicolumn{2}{|c|}{ Imóveis } & \multicolumn{2}{c|}{ Área total } & \multirow{2}{*}{$\begin{array}{c}\text { Área média } \\
\text { (em ha) }\end{array}$} \\
\cline { 2 - 5 } & Número de imóveis & $\mathbf{E m} \%$ & Em ha & Em \% & 4,7 \\
\hline Até 10 & 1.744 .540 & 33,7 & 8.215 .337 & 1,4 & 4,7 \\
\hline De 10 a 100 & 2.709 .158 & 52,3 & 90.005 .536 & 15,7 & 120,6 \\
\hline De 100 a 500 & 563.346 & 10,8 & 116.156 .530 & 20,3 & 206,2 \\
\hline De 500 a 2000 & 125.351 & 2,4 & 114.568 .372 & 20,1 & 2075,2 \\
\hline Mais de 2000 & 39.250 & 0,8 & 242.795 .145 & 42,5 & $6.185,9$ \\
\hline TOTAL & $\mathbf{5 . 1 8 1 . 6 4 5}$ & $\mathbf{1 0 0 , 0}$ & $\mathbf{5 7 1 . 7 4 0 . 9 1 9}$ & $\mathbf{1 0 0 , 0}$ & $\mathbf{1 1 0 , 3}$ \\
\hline
\end{tabular}

Fonte: Incra. Sistema Nacional de Cadastro Rural. 
O atual modelo agrícola está voltado fundamentalmente para as atividades do agronegócio que reúne em sua cadeia produtiva capital agrário, industrial e financeiro, nacional e internacional. A agricultura familiar e a camponesa permanecem com menores investimentos e resistindo a pressão do modelo hegemônico, que produz tecnologia voltada para a monocultura e inflaciona o mercado de terras, de maneira a dificultar uma reforma agrária ampla e maciça e uma política agrícola de bases agroecológicas. Os rebatimentos desse processo sobre o mundo do trabalho são evidentes: a desertificação do campo em áreas de monocultura, a diminuição dos agricultores familiares e camponeses, a precarização do trabalho assalariado, a concentração dos maiores índices de pobreza em área rural e o acirramento da luta pela terra.

Neste artigo, a pesquisa enfoca as atividades do agronegócio canavicultor em duas regiões do interior do estado de São Paulo, onde as atividades do setor reclamam para si o símbolo da modernidade decorrente da incorporação de tecnologia no âmbito da produção e do gerenciamento da força de trabalho. Uma imagem que não se sustenta do ponto de vista das relações de trabalho conforme atesta uma vasta literatura a respeito (Silva, 1999; Novaes e Alves, 2007; Gomes, 2012; Sant'Ana, 2012). Os trabalhadores que desenvolvem atividades rurais no setor canavieiro em função do ritmo e da intensidade do trabalho, são precocemente descartados, seja em virtude de um possível adoecimento ou da mecanização da colheita da cana que se acentuou nos últimos cinco anos. Como na área rural dos municípios dessa região predomina a monocultura canavieira, os trabalhadores rurais dificilmente encontram outra opção de trabalho, e quando a encontram, são ainda mais precárias. Os rebatimentos desse processo são uma legião de trabalhadores com mais de quarenta anos desempregados, descartados de forma permanente do trabalho. A busca da política de assistência é, portanto, o único caminho possível, ainda que não se dê de forma a substituir a busca pelo trabalho. ${ }^{3}$ Somam-se a esses trabalhadores desempregados outros que ainda permanecem na atividade agrícola, mas que não conseguem auferir com seu trabalho os rendimentos suficientes para a sua manutenção e a de sua família.

A discussão sobre o papel das políticas sociais no atual contexto e a participação do trabalhador rural pressupõe, no entanto, uma retomada, mesmo que

3. Na pesquisa de campo realizada, impressiona o esforço dos trabalhadores em buscar alternativas de trabalho, mesmo que extremamente precarizado, em outras atividades. 
pontual, dos marcos legais e políticos que estruturam a atual configuração das políticas de seguridade social.

A Constituição de 1988 foi um marco do ponto de vista dos direitos sociais, pois estabeleceu a saúde, a assistência e a previdência social como políticas estruturantes do tripé da seguridade social.

As lutas e embates estabelecidos na década de 1980 pelos diversos segmentos da classe trabalhadora trouxeram para a cena política uma diversidade de atores e instituições que respaldaram, no âmbito da sociedade, uma abertura política capaz de marcar positivamente o encaminhamento de diversas reivindicações de direitos de seguridade.

No entanto, a materialização de alguns direitos da classe trabalhadora na Constituição brasileira, não impediu que esta, acima de tudo, reproduzisse os interesses do capital. A Constituição Cidadã, como é conhecida a lei máxima de 1988, respalda fundamentalmente a ordem do capital e reafirma, ao manter intocados, a propriedade privada e os interesses econômicos da ordem capitalista.

É nessa Carta Magna, porém, que alguns direitos sociais são explicitados como direitos de cidadania, como é o caso da política de seguridade social.

As políticas de Seguridade Social, nas quais se incluem a Saúde a Previdência e a Assistência Social, podem ser consideradas produto histórico das lutas dos trabalhadores na medida em que respondem a necessidades inspiradas em princípios e valores socializados pelo campo do trabalho e reconhecidos pelo Estado e pelo empresariado. Todavia, na dinâmica reprodutiva do capitalismo, esta constatação não exime ser o campo da Seguridade Social também um ambiente da intervenção política das classes dominantes, seja como mecanismo de integração social, seja como meio de compatibilizar capitalismo, direitos sociais e democracia. Nestes termos, a Seguridade Social é por definição um campo de disputas, seja por parte do trabalho, seja por parte do capital que continuamente tenta adequá-la aos seus interesses. (Mota, 2006, p. 165)

A assistência social que historicamente era concebida como favor ou benesse, passa a constituir-se como política pública. Vários marcos legais foram sendo construídos (e desconstruídos) no sentido de viabilizar a efetivação das políticas de seguridade, principalmente da saúde e da assistência social que tem (ou deveriam ter) um caráter universal e não contributivo. 
As leis orgânicas da saúde e assistência social e, depois, a Política Nacional de Assistência Social (PNAS) significaram avanços nessas duas áreas, pois instituíram o direito universal à saúde e colocaram a assistência social como direito, contrapondo-se a caridade, filantropia e benesses como até então era tratada. Ocorre que no tensionamento das classes sociais, numa conjuntura de desmobilização do movimento de massa, os interesses do capital tem se espraiado por todas essas searas, principalmente na saúde, que tem grande potencial de mercantilização ${ }^{4}$.

No plano legal, tanto a política da saúde quanto da assistência vão ter três diretrizes básicas: a descentralização política administrativa, a formação dos conselhos nas diversas esferas do governo (nacional, estadual e municipal) e participação da comunidade. A efetivação desses princípios não está sendo algo fácil ou possível em face das opções políticas desenvolvidas pelos diversos governos, mas constituem-se como bandeiras de lutas dos segmentos mais organizados até os dias atuais.

O desrespeito contínuo às proposições das leis criou o que um estudioso no assunto denominou de "Estado de Mal-Estar Social" (Vieira, 1992). Os governos atuaram em duas frentes no esvaziamento da seguridade social: no plano jurídico fez reformas/revisões na Constituição de maneira a retirar elementos fundamentais...; e, no plano prático-concreto promoveu um "modelo de desenvolvimento que inviabilizou as bases de sustentação econômico-financeiras da implantação desta alternativa" (Vieira, 1992).

A política social do governo FHC ficou subordinada a sua estratégia macroeconômica, que por sua vez foi ditada pelo grande capital. Previu a participação contributiva e a segmentação dos usuários, seguindo uma lógica privatista e mercantilista que apontou claramente para desresponsabilização do Estado em face da sociedade e promoveu insistentes investidas no sentido de privatizar serviços de saúde e previdência social.

No que se refere aos mecanismos de descentralização previstos, o governo na área da assistência repassou para os estados e municípios responsabilidades, sem a

4. Isso fica evidente nos últimos anos pelo avanço da privatização de diversos serviços de saúde e, recentemente pela criação Empresa Brasileira de Serviços Hospitalares (EBSERH), destinada a gerir os hospitais universitários numa perspectiva claramente mercantil. Nessa área, as mobilizações sociais têm sido bastante expressivas, e destaco aqui a importância da Frente Nacional Contra a Privatização da Saúde. 
contrapartida financeira, o que gerou distorções fundamentais na construção da política. O princípio legal instituído que prevê o comando único das ações na esfera da saúde e assistência foi sistematicamente desrespeitado.

Consequentemente, isso trouxe diversos entraves à efetivação das políticas sociais nos municípios. Os espaços de participação da população nos conselhos nem sempre garantem um mínimo de discussão política para o direcionamento das ações, conforme preveem os instrumentos legais. Sem a pressão de movimentos organizados que lhe deem bases, a maioria dos conselhos tornou-se instâncias esvaziadas de poder, que se limitam a legitimar os desrespeitos dos governos federal, estaduais e municipais na efetivação do que seria o direito fundamental da população.

No governo Lula, a prioridade do combate à pobreza foi feito de maneira a promover a assistência como prioridade sobre outras políticas, porém não na diretriz proposta pela Lei Orgânica da Assistência, mas como ênfase nos programas focalizados de renda, especialmente o Bolsa Família (BF) e o Benefício de Prestação Continuada (BPC), esse alocado no Ministério de Desenvolvimento Social e Combate a Fome (MDS) e que consome quase $90 \%$ dos orçamentos de todos os outros programas. Mota (2006) fala em fetichização da assistência, ou seja, à medida que o governo não responde aos interesses fundamentais do trabalho, amplia o campo da assistência social, via programas focalizados de renda.

Na pesquisa realizada, ainda que os dados coletados tratem da saúde e assistência, neste artigo o foco será a participação do trabalhador rural na política assistência social em municípios de pequeno porte (até 50 mil habitantes) da região de Franca e Ribeirão Preto, nordeste do estado de São Paulo.

\section{A participação dos trabalhadores da região de Franca e Ribeirão Preto (SP) na política de assistência social}

Os dados apresentados a seguir, conforme já mencionado, são resultado da pesquisa realizada sobre o acesso do trabalhador rural à política de assistência social em municípios de até 50 mil habitantes das regiões de Franca e Ribeirão Preto, ambas no interior do estado de São Paulo. 
O objetivo da pesquisa realizada foi dar visibilidade à relação capital/trabalho na definição das refrações da questão social que se expressam no cotidiano do Serviço Social quando este participa da efetivação das políticas sociais, em especial as de assistência social e de saúde.

Para tanto, foi realizada uma pesquisa ampla, envolvendo 26 municípios ao todo, mas, na área da assistência social em específico, foram envolvidos dez municípios das regiões de Franca e Ribeirão Preto. ${ }^{5}$ As dificuldades da coleta no Cadastro Único do governo federal fizeram com que houvesse diversificação dos instrumentos a ser analisados. Procedeu-se com a coleta de dados em três programas, dois de âmbito municipal e um federal: o Programa Saúde da Família, ${ }^{6}$ o Programa de Acolhimento Social e Cadastro Único do governo federal. ${ }^{7}$ Foram analisados 1.562 instrumentos e realizadas as entrevistas individuais com técnicos e sindicalistas. Além das entrevistas individuais, foram visitados dois equipamentos de dois municípios (um da região de Ribeirão Preto e outro de Franca) para abordagem dos usuários do Bolsa Família com intuito de cruzar as informações com os dados quantitativos, conforme será apresentado nesse artigo; a equipe conversou com 26 trabalhadores que estavam realizando alguma ação referente ao Bolsa Família.

Devido aos limites que um artigo impõe para a apresentação dos dados, iremos focar apenas na apresentação dos dados que evidenciam a presença do trabalhador rural na política de assistência social nos municípios pesquisados.

Na Tabela 1 e no Gráfico 1 são apresentados os dados gerais que evidenciam a presença do trabalhador rural na política pública de assistência social.

5. A proposição inicial era atingir doze municípios, mas dois municípios da região de Ribeirão Preto, depois de muitas tentativas e vários contatos e deslocamentos até o município, negaram a realização da pesquisa. Foi eleito outro município, mas este também não permitiu.

6. Embora esse programa seja da área da saúde, as informações coletadas eram voltadas para a caracterização da presença do trabalhador rural na política pública e foram tabuladas com os dados da área da assistência social.

7. Essa diversidade de instrumento foi necessária devido a três elementos fundamentais: a autorização de acesso, o tipo de instrumento encontrado e a qualidade das informações disponíveis. Na busca por informações mais completas foram utilizados os dados do Cadastro Único quando este possuía alguns documentos que pudessem completar as informações, sempre bastante restritas no item sobre ocupação; as fichas do Programa Saúde da Família foram utilizadas quando o município não abriu seus fichários na área da assistência ou quando este não tinha um instrumental diferente do CadÚnico. 
Tabela 2. Participação dos trabalhadores na política de assistência social das regiões de Franca e Ribeirão Preto

\begin{tabular}{|l|c|c|c|}
\cline { 2 - 4 } \multicolumn{1}{c|}{} & Região de Franca & Região de Ribeirão Preto & Total \\
\hline Com trabalhador rural & 209 & 157 & 366 \\
\hline Com ex-trabalhador rural & 16 & 53 & 69 \\
\hline Sem trabalhador rural & 552 & 351 & 903 \\
\hline $\begin{array}{l}\text { Não consta informação sobre a } \\
\text { ocupação }\end{array}$ & 185 & 39 & 224 \\
\hline
\end{tabular}

Gráfico 1. Participação dos trabalhadores na política de assistência social das regiões de Franca e Ribeirão Preto

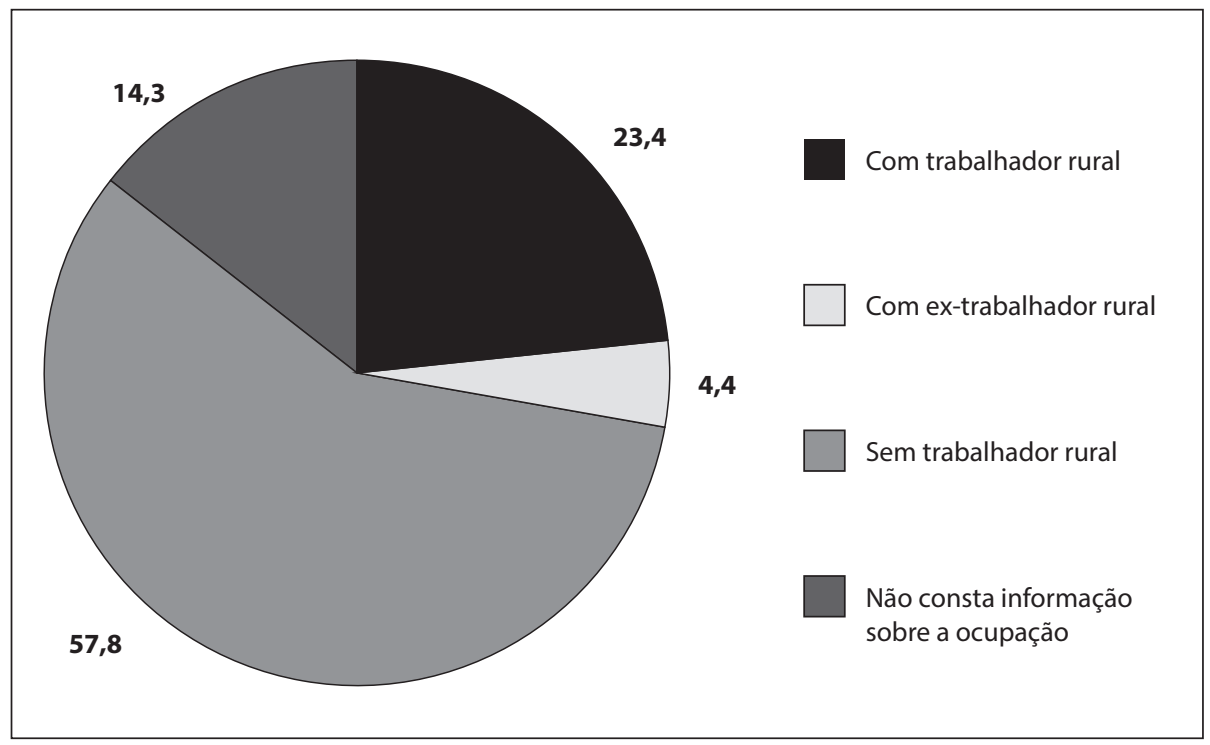

Fonte: Dados da pesquisa.

A Tabela 2 mostra que dentre as 1.562 fichas computadas, 903 (57,8\%) não registravam a presença do trabalhador rural. É importante destacar, no entanto, que quando no instrumento não havia como discriminar a profissão ou a atividade desenvolvida, computou-se como não tendo o trabalhador rural. Somente as fichas 
onde não havia dados explícitos sobre ocupação é que foram tabulados como não contendo essa informação. Ainda assim, o número de não registros da ocupação foi 224 fichas, o que equivale a $14,3 \%$ do total.

Só em três municípios, as fichas traziam informações discriminando trabalhadores e ex-trabalhadores rurais.

Os trabalhadores rurais aparecem em 366 fichas $(23,4 \%)$ dos usuários da assistência social. Somados com os ex-trabalhadores são 435 e representam $27,8 \%$. Se forem retiradas as fichas que não tem informação sobre o trabalho, os dados indicam que os trabalhadores rurais somam 32,5\% dos usuários da assistência social.

Este número poderia ser bem maior se o registro não fosse tão precário. Para evidenciar essa afirmação, serão apresentados aqui os dados de dois municípios que a equipe fez uma conferência qualitativa dos dados abordando diretamente as famílias que estavam nos equipamentos sociais. Um município é classificado de nível 2 (30 a 50 mil habitantes) e o outro que é de nível 1 (até 20 mil habitantes).

No município acima de 20 mil habitantes foram abordadas dezesseis famílias que recebiam o Bolsa Família e que foram ao plantão do Programa Saúde da Família para pesar seus filhos. Nas abordagens realizadas dentre as dezesseis famílias, em sete havia ex-cortador de cana e, destes apenas dois ainda permaneciam trabalhando em área rural: um como aplicador de veneno na canavicultura e outro como embalador de manga. Dois estavam trabalhando como serventes de pedreiro, um como pedreiro e as duas mulheres, ex-cortadoras de cana, estavam desempregadas. No município, segundo os dados quantitativos, a presença do trabalhador ou ex-trabalhador rural na assistência social é $11,1 \%$; na pesquisa qualitativa é de $43,7 \%$.

O mesmo ocorre no município de até 20 mil habitantes da região de Franca. Na sequência, apresentaremos os dados gerais dos municípios de até 20 mil habitantes que têm como base econômica a cultura canavieira onde fica mais evidente a participação do trabalhador rural na política de assistência social e, depois, as dificuldades apresentadas pelos registros.

A Tabela 2 mostra a presença do trabalhador rural, segundo os dados quantitativos levantados, agrupados agora pelo tamanho do município. 
Tabela 3. Participação dos trabalhadores rurais na política de assistência social nos municípios de até $\mathbf{2 0}$ mil habitantes

\begin{tabular}{|c|c|c|c|}
\hline Com trabalhador rural & $\begin{array}{c}\text { Com ex-trabalhador } \\
\text { rural }\end{array}$ & $\begin{array}{c}\text { Sem trabalhador } \\
\text { rural }\end{array}$ & $\begin{array}{c}\text { Não consta informação } \\
\text { sobre a ocupação }\end{array}$ \\
\hline 203 & 14 & 269 & 14 \\
\hline
\end{tabular}

Fonte: Dados da pesquisa.

Gráfico 2. Participação dos trabalhadores rurais na política de assistência social nos municípios de até $\mathbf{2 0}$ mil habitantes

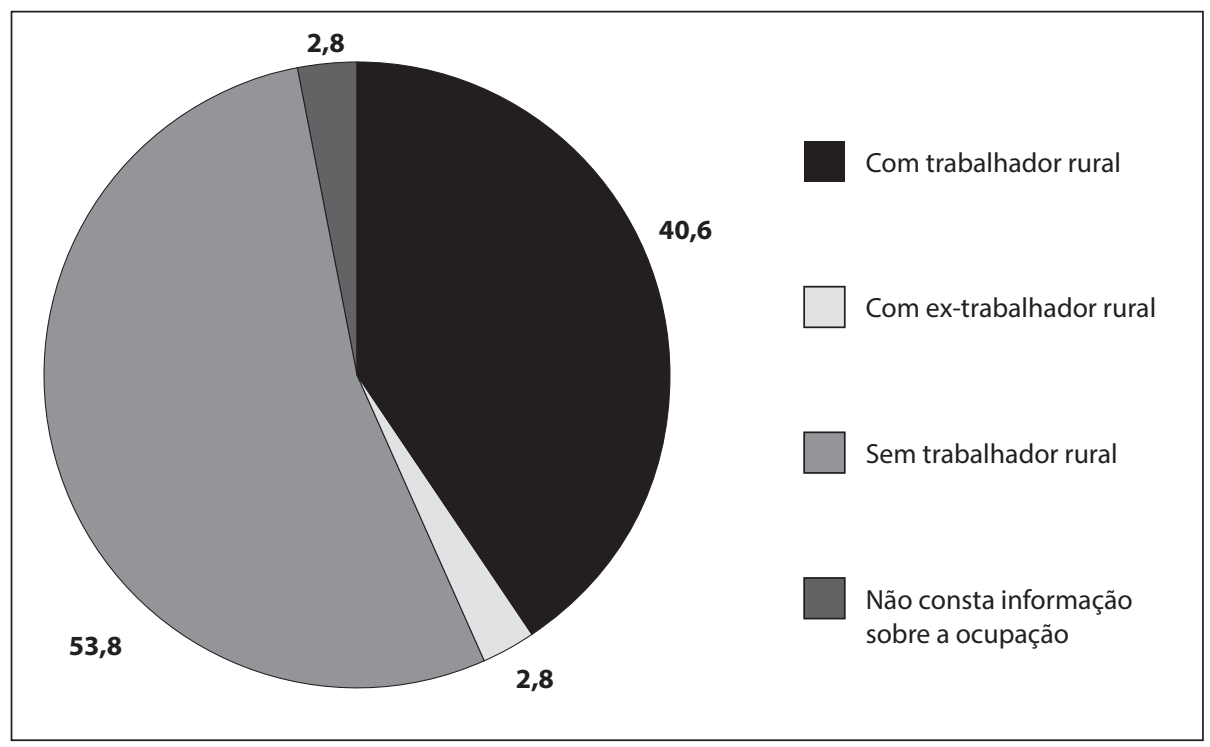

Fonte: Dados da pesquisa.

Foram consultadas cem fichas de cinco municípios de até vinte mil habitantes, três da região de Franca e dois da região de Ribeirão Preto, perfazendo um total de 500 instrumentos. A presença de trabalhadores rurais e ex-trabalhadores é de 203 e catorze registros, respectivamente. Juntos representam 43,5\% dos usuários (217 famílias). As fichas sem trabalhadores rurais somam 269 registros, o que equivale a 53,8\% do público usuário. As fichas sem informação sobre ocupação foram catorze e representam $2,8 \%$ do universo pesquisado. 
É importante mencionar que também nos municípios de pequeno porte esse número seria maior se os registros não fossem tão lacunares no quesito ocupação.

Em um dos municípios foram consultados, conforme o previsto, cem formulários do Cadastro Único, porém o procedimento para a coleta dos dados teve uma particularidade. Enquanto alguns membros da equipe procediam à coleta nos documentos, outro realizava entrevista com as pessoas que estiveram presentes no equipamento para preencher o Cadastro. Foram entrevistadas dez pessoas, que nos deram mais informações sobre a trabalho dos membros da família.

Nas noventa fichas analisadas nos cadastros, a proporção de trabalhadores rurais foi de aproximadamente $8,9 \%$, isto é, apenas oito fichas eram de famílias com pelo menos um trabalhador rural. Nas outras 82 restantes (aproximadamente 91\%) não havia nenhuma menção aos trabalhadores rurais.

O acompanhamento das entrevistas para o preenchimento do CadÚnico representou um aprofundamento do dado, de forma que foi possível ouvir os relatos dos trabalhadores que foram até o Departamento de Promoção Social do município para incluir a família no CadÚnico. Das dez entrevistas acompanhadas, sete eram com membros de famílias com pelo menos um trabalhador rural, representando $70 \%$ de trabalhadores rurais.

As duas profissionais do Serviço Social responsáveis pela assistência social no município - tanto no Cras como no Departamento de Promoção Social — nas entrevistas concedidas relataram que o trabalhador rural era o principal usuário da política de assistência social do município. ${ }^{8}$ A profissional há mais tempo no município inclusive aponta a proporção de trabalhadores rurais - 70\% - e tal dado coincide com o acompanhamento das entrevistas por parte das pesquisadoras.

É interessante observar que o trabalhador rural, que no Cadastro Único era um segmento que representava menos de $10 \%(8,9 \%)$ nos dados quantitativos, na abordagem qualitativa passa a $70 \%$ do público da assistência social. No registro geral da participação desse segmento na política usou-se a porcentagem referente às 100 fichas e que na média geral significou que o município teve um índice de $15 \%$ de trabalhadores rurais.

A presença marcante do trabalhador rural na política pública de assistência social em município de pequeno porte é resultado do modelo de desenvolvimento agrário baseado na monocultura que desertifica o campo e utiliza insumos químicos

8. Esse era um dado de percepção, pois não havia um levantamento que pudesse comprovar. Aliás, essa não quantificação é uma realidade em praticamente todos os municípios. 
e maquinários como componentes fundamentais do processo produtivo, empregando pouca força de trabalho e, quando o faz, orienta-se fundamentalmente pela lógica do lucro, ainda que o marketing social divulgue exatamente o contrário.

Recorrer à política de assistência social é, pois, condição necessária frente a precarização do trabalho ou a condição permanente de desemprego. Nos municípios de até vinte mil habitantes, essa realidade é ainda mais preocupante, pois a área rural é praticamente tomada pela cultura canavieira e as atividades ligadas ao setor passam a ser a única fonte de emprego. ${ }^{9}$

A assistente social de um município de menos de vinte mil habitantes fala sobre a relação entre a mecanização da lavoura canavieira e o aumento da demanda.

Sim, por conta das máquinas, né? Agora a modificação da cana é outra, né? É máquina, né? Não é dos trabalhadores em si, então as coisas vão modificando, então a procura aqui é meio relativa, não posso afirmar $100 \%$, mas acho que uns $20 \%$ ou $30 \%$ de aumento da demanda. [...] Porque é onde eles não se qualificam né? Então, eles não têm muito onde trabalhar, né? E o município não oferece isso, então aqueles que não conseguiram trabalho na "roça" que eles falam assim: é mais complicado porque eles não tem uma qualificação. [...] aqui é só cana. (Assistente social A da região de Franca)

A profissional atribui as dificuldades de reinserção do trabalhador a sua falta de qualificação profissional. Afinal, em área rural só tem essa opção de emprego. À medida que esse modelo de agricultura é visto como única opção, não se faz a crítica pensando em uma alternativa de pluriatividade voltada para a produção familiar, que, com certeza, ampliaria as opções de trabalho.

$\mathrm{Na}$ canavicultura, nos últimos anos, ampliou-se a utilização de máquinas colhetadeiras. Esta faz o trabalho de muitos homens e, portanto, o desemprego é inevitável. Como afirma Andrade Junior e Maniglia (2011, p. 287):

Embora a colheita mecanizada empregue alguns indivíduos em sua estrutura de produção, o número total de postos de trabalho oferecidos é significativamente inferior àqueles oferecidos no sistema de colheita manual, sendo consequência dessa transição produtiva a acentuação dos problemas sociais nas regiões sucroalcooleiras através da geração do desemprego estrutural.

9. As áreas dos municípios pesquisados têm cerca de 70\% de seu território ocupado com a canavicultura. Em alguns, descontado o perímetro urbano, praticamente não há outras culturas além da cana-de-açúcar. 
As outras atividades desenvolvidas nos municípios ou nos arredores são bastante incipientes; via de regra, são também vinculadas às atividades do agronegócio. Nessa pesquisa, as culturas mencionadas que empregam os trabalhadores descartados pelas usinas (e ainda têm capacidade laborativa) foram: o café, a laranja e o milho. As condições de trabalho em todas essas culturas são muito ruins. Grande parte dos trabalhadores não é registrada, a remuneração é inferior ao salário mínimo, o uso do IPI não é frequente e a oferta de trabalho é sazonal. Nos registros de um dos municípios em que havia maiores informações, a remuneração dos trabalhadores que apanhavam laranja nunca era superior a meio salário mínimo. Outro dado importante: a insistência do trabalhador em permanecer trabalhando: mesmo doente, em condições informais, com péssima remuneração, ele continua a sua busca incessante pelo trabalho.

\section{Considerações finais}

A apreensão da centralidade do trabalho no cotidiano profissional é um desafio que exige preparo teórico metodológico. A pobreza e o que se convencionou chamar de vulnerabilidades sociais só podem ser devidamente analisados a partir das mediações postas pelo trabalho, especialmente nesse contexto onde os monopólios se destacam nas diversas esferas da produção e da reprodução social dando o tom da vida e do trabalho.

Ainda que essa realidade se apresente mediada por $n$ elementos que compõem os complexos sociais, a apreensão de seus nexos causais é fundamental. Se o profissional que atua em municípios de pequeno porte consegue identificar a relação entre esse modelo de agricultura e o recorrente desemprego da população, poderá ter uma postura mais adequada frente a essa demanda que surge no seu cotidiano profissional. Isso permitirá um registro mais qualificado da situação ocupacional desse usuário e ainda um foco mais adequado para o trabalho e os programas voltados para essa população.

Outro elemento importante é que a percepção da nocividade do monocultura pode permitir que o assistente social, em seu trabalho de acompanhamento das famílias, seja em âmbito individual ou coletivo, possa colocar em pauta temas como direitos trabalhistas, função social da propriedade, reforma agrária, agrotóxicos, desertificação do campo, pluriatividade, enfim, uma gama de assuntos que poderão fomentar o interesse do trabalhador em buscar outras alternativas para o campo. 
O trabalho socioeducativo do Serviço Social pode fortalecer essa população "vulnerável" para se identificar como sujeito coletivo, mas para isso é preciso ter claro que, além de usuários da política de assistência social, são trabalhadores que podem resistir e lutar e que alternativa da luta pela terra existe desde sempre nesse país colonizado.

Recebido em: 15/7/2014 - Aprovado em: 4/8/2014

\section{Referências bibliográficas}

ANDRADE JUNIOR, J. R. P.; MANIGLIA, E. Modernização perversa e degradação ambiental através da proibição gradativa da queima da cana-de-açúcar. In: SANT'ANA CARMO, O. A.; LOURENÇO, E. A. de S. Questão agrária e saúde dos trabalhadores: desafios para o século XXI. São Paulo: Cultura Acadêmica, 2011.

CASTELO, R. O novo desenvolvimentismo e a decadência ideológica do pensamento. Serviço Social \& Sociedade, São Paulo, n. 112 (Especial), p. 613-636, 2012.

. O social-liberalismo brasileiro e a miséria ideológica da economia do bem-estar. In: MOTA, A. E. (Org.). Desenvolvimentismo e construção de hegemonia: crescimento econômico e reprodução da desigualdade. São Paulo: Cortez, 2012. p. 46-77.

COBO, B. Políticas focalizadas de transferência de renda: contextos e desafios. São Paulo: Cortez, 2012.

COUTO, B.; YAZBEK, M. C.; RAICHELIS, R. A política de assistência social e o Suas: apresentando e problematizando fundamentos e conceitos. In: COUTO, B. et al. (Orgs.). O Sistema Único de assistência social no Brasil: uma realidade em movimento. São Paulo: Cortez, 2010.

GOMES. J. A. Do trabalho penoso à dignidade do trabalho: o itinerário de canavieiros no enfoque da psicologia do trabalho. Aparecida: Ideias \& Letras, 2012.

GONÇALVES, R. O novo desenvolvimentismo e o liberalismo enraizado. Serviço Social \& Sociedade, São Paulo, n. 112, p. 637-671, 2012a.

. Redução da desigualdade da renda no governo Lula: análise comparativa. In: BEHRING, E.; BOSCHETTI, I.; GRANERMANN, S.; SALVADOR, E. (Orgs.). Financeirização, fundo público e política social. São Paulo: Cortez, 2012b. p. 13-30. 
LUKÁCS, G. Ontologia del ser social: el trabajo. Buenos Aires: Herramienta, 2004.

. Ontologia do ser social: os princípios fundamentais de Marx. Tradução C. N. Coutinho. São Paulo: Livraria Editora Ciências Humanas, 1979.

MARX, K. Para a crítica da economia política: salário, preço e lucro. O rendimento e suas fontes. São Paulo: Abril Cultural, 1982.

. O capital: crítica da economia política. São Paulo: Nova Cultural, 1983. Livro I, v. I.

.O capital: crítica da economia política. 3. ed. São Paulo: Nova Cultural, 1988. v. II. . Manuscritos econômico-filosóficos. São Paulo: Boitempo, 2004.

MOTA, A. E. (Org.). Desenvolvimentismo e construção de hegemonia: crescimento econômico e reprodução da desigualdade. São Paulo: Cortez, 2012.

. O mito da assistência social: ensaios sobre Estado, política e sociedade. Recife: UFPE, 2006.

. MARANHÃO, C. H.; SITCOVSKY, M. O Sistema Único de Assistência Social e a formação profissional. Serviço Social \& Sociedade. São Paulo, ano XXVI, n. 87 (Especial), 2006.

NETTO, Paulo J. Capitalismo monopolista e Serviço Social. 2. ed. São Paulo: Cortez, 1996.

NOVAES, J. R.; ALVES, F. (Orgs.). Migrantes: trabalho e trabalhadores no complexo agroindustrial canavieiro (os heróis do agronegócio brasileiro). São Carlos: EdufsCar, 2007.

SANT’ANA, R. S. Trabalho bruto no canavial: questão agrária, assistência e Serviço Social. São Paulo: Cortez. 2012.

. Trabalho e política pública: a participação dos trabalhadores do complexo agroindustrial canavieiro na política de seguridade social. Projeto CNPq, 2010-13.

SILVA, M. A. de M. Errantes do fim do século. São Paulo: Edunesp, 1999. .A morte nos canaviais paulistas. Reforma agrária, São Paulo, v. 33, n. 2, p. 111-143, 2006.

. Agrocombustíveis como solução? A vida por um fio no eito dos canaviais. São Paulo: Centro de Capacitação da Juventude, 2008.

SITCOVSKY, M. A reconciliação entre assistência social e trabalho: o impacto do Bolsa Família. In: MOTA, A. E. Desenvolvimentismo e construção de hegemonia: crescimento econômico e reprodução da desigualdade. São Paulo: Cortez. 2012.

VIEIRA, E. Democracia e política social. São Paulo: Cortez, 1992. (Col. Polêmicas de Nosso Tempo, n. 49.) 